\title{
Estimate of External Background Radiation Interference on a Tomography Scanner
}

\author{
G. P. Roberson, C. M. Logan
}

\section{July 21, 2000}

\section{U.S. Department of Energy}

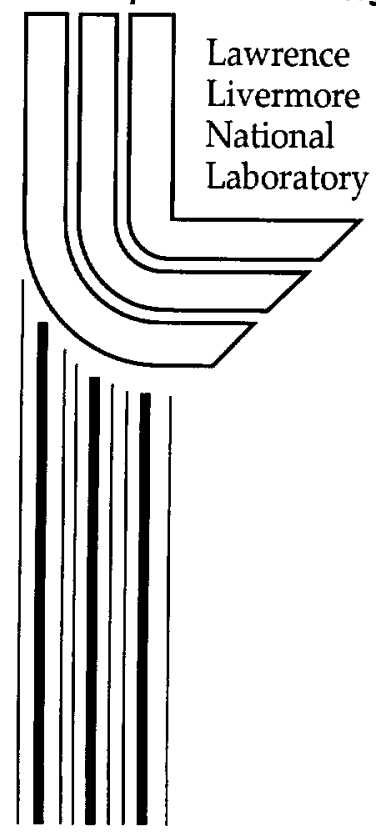




\section{DISCLAIMER}

This document was prepared as an account of work sponsored by an agency of the United States Government. Neither the United States Government nor the University of California nor any of their employees, makes any warranty, express or implied, or assumes any legal liability or responsibility for the accuracy, completeness, or usefulness of any information, apparatus, product, or process disclosed, or represents that its use would not infringe privately owned rights. Reference herein to any specific commercial product, process, or service by trade name, trademark, manufacturer, or otherwise, does not necessarily constitute or imply its endorsement, recommendation, or favoring by the United States Government or the University of California. The views and opinions of authors expressed herein do not necessarily state or reflect those of the United States Government or the University of California, and shall not be used for advertising or product endorsement purposes.

This work was performed under the auspices of the U. S. Department of Energy by the University of California, Lawrence Livermore National Laboratory under Contract No. W-7405-Eng-48.

This report has been reproduced directly from the best available copy.

Available electronically at http://www.doc.gov/bridge

Available for a processing fee to U.S. Department of Energy

And its contractors in paper from

U.S. Department of Energy

Office of Scientific and Technical Information

P.O. Box 62

Oak Ridge, TN 37831-0062

Telephone: (865) 576-8401

Facsimile: (865) 576-5728

E-mail: reports@adonis.osti.gov

Available for the sale to the public from

U.S. Department of Commerce

National Technical Information Service

5285 Port Royal Road

Springfield, VA 22161

Telephone: (800) 553-6847

Facsimile: (703) 605-6900

E-mail: orders@ntis.fedworld.gov

Online ordering: http://www.ntis.gov/ordering.htm

OR

Lawrence Livermore National Laboratory Technical Information Department's Digital Library

http://www.llnl.gov/tid/Library.html 


\title{
ESTIMATE OF EXTERNAL BACKGROUND RADIATION INTERFERENCE ON A TOMOGRAPHY SCANNER
}

\author{
G. Patrick Roberson and Clint M. Logan \\ Lawrence Livermore National Laboratory \\ July 21,2000
}

\begin{abstract}
We have estimated interference from external background radiation for a computed tomography (CT) scanner. Our intention is to estimate the interference that would be expected for the high-resolution SkyScan 1072 desk-top x-ray microtomography system. The SkyScan system uses a Microfocus $x$-ray source capable of a $10-\mu \mathrm{m}$ focal spot at a maximum current of $0.1 \mathrm{~mA}$ and a maximum energy of $130 \mathrm{kVp}$. All predictions made in this report assume using the $\mathrm{x}$-ray source at the smallest spot size, maximum energy, and operating at the maximum current. Some of the systems basic geometry that is used for these estimates are:
Source-to-detector distance:
$250 \mathrm{~mm}$, Minimum object-to-detector distance:

Maximum object-to-detector distance: $230 \mathrm{~mm}$.

This is a first-order, rough estimate of the quantity of interference expected at the system detector caused by background radiation. The amount of interference is expressed by using the ratio of exposure ${ }^{1}$ expected at the detector of the CT system. The exposure values for the SkyScan system are determined by scaling the measured values of an $x$-ray source and the background radiation adjusting for the difference in source-to-detector distance and current. The $x$-ray source that was used for these measurements was not the SkyScan Microfocus $x$-ray tube. Measurements were made using an $x$-ray source that was operated at the same applied voltage but higher current for better statistics.
\end{abstract}

Exposure from the $x$-ray source was measured using a 660 Victoreen meter with a 660-3 probe (SN 767). The meter was last calibrated $5 / 1999$ and is due $5 / 2000$. The $x$-ray source that was used was a $160 \mathrm{kVp}, 33 \mathrm{~mA}$ Philips tube with a $\mathrm{W}$-anode. The model number of the $x$-ray system is MG 161. Measurements of exposure were taken at two different energies, $80 \mathrm{kVp}$ and $130 \mathrm{kVp}$. Measurements were taken at three different source-to-detector distances: $1,0.5$, and 1.2 meters. At 1 meter, measurements were taken for three different cases. First, the x-ray source was not filtered. Second, the source was filtered with 5 mil of $\mathrm{Cu}$. Third, the source was filtered with $16.5 \mathrm{mil}$ of $\mathrm{Cu}$. For both the 0.5 and 1.2 meter measurements, the $\mathrm{x}$-ray source was unfiltered and filtered with 5 mil of $\mathrm{Cu}$. Each exposure measurement was performed for an integration period of 1 minute except one measurement that was taken for an integration period of 2 minutes. The 2-minute integration was performed for validation of the test set up and procedure. Measurement were taken for a tube current of $10 \mathrm{~mA}$ in all cases except one where the unfiltered $x$-ray source located at $0.5 \mathrm{~m}$ from the detector saturated the detector. For this case the source current was lowered to $1 \mathrm{~mA}$ to avoid saturation. The measurements were repeated at least 3 times for each position, energy, and filter case observed.

Values were scaled for expected exposure from the SkyScan $x$-ray source using the average of the repeated measurements described above. The exposure scaling is dependent on system geometry and the maximum current available at the minimum spot size and maximum voltage. The current used was $0.1 \mathrm{~mA}$. The values are shown in Tables 1-3 and are labeled "Expected at $250 \mathrm{~mm}, 0.1 \mathrm{~mA}$.

\footnotetext{
${ }^{1}$ Exposure is defined in terms of the charge due to ionization created by the secondary electrons formed within a volume element of air and mass, when the secondary electrons are completely stopped in air. The SI unit of exposure is coulomb per kilogram $(\mathrm{C} / \mathrm{kg})$ and $1 \mathrm{R}($ roentgen $)=2.58 \times 10^{-4} \mathrm{C} / \mathrm{kg}$.
} 
Values used for estimating interference were determined by averaging the expected exposures calculated for the SkyScan system. The only exception is that the value for the unfiltered measurement at 0.5 meters was not used in determining the average. At 0.5 meters, there is less attenuation due to air of the low energy $x$-rays. This most likely explains the higher exposure rate for the unfiltered case at 0.5 meters. The filtered case does not show this difference because the low energy $x$-rays are absorbed in the filter before they are absorbed in air. This value is not used because it is not certain that the $x$-rays at these energies would cause the detector to scintillate before they are absorbed in the outer layers. The following are the average scaled exposure values for an $x$-ray source operated at $0.1 \mathrm{~mA}$ located at $250 \mathrm{~mm}$ from the detector:

$\begin{array}{ll}\text { Unfiltered } & 13.858 \mathrm{R} / \mathrm{min}, \\ \text { Filtered with } 5 \mathrm{mil} \mathrm{Cu} & 1.416 \mathrm{R} / \mathrm{min}, \\ \text { Filtered with } 16.5 \mathrm{mil} \mathrm{Cu} & 0.662 \mathrm{R} / \mathrm{min} .\end{array}$

We also calculated the exposure values expected from the SkyScan $x$-ray source. This work was performed by Clint Logan and is summarized in appendix A. The exposure was calculated for an x-ray source operated at $130 \mathrm{kVp}, 1 \mathrm{~mA}$, and measured at 1 meter away. Values for the SkyScan geometry and $x$-ray source current can be determined from these calculated values and are:

\begin{tabular}{|c|c|c|}
\hline & 1 meter $1 \mathrm{~mA}$ & $\begin{array}{l}\text { SkyScan system } \\
250 \mathrm{~mm} 0.1 \mathrm{~mA}\end{array}$ \\
\hline Unfil & $97 \mathrm{R} / \mathrm{min}$ & $155 \mathrm{R} / \mathrm{min}$, \\
\hline with $5 \mathrm{mil} \mathrm{Cu}$ & $2.4 \mathrm{R} / \mathrm{min}$ & $3.84 \mathrm{R} / \mathrm{min}$, \\
\hline with 16.5 mil Cu & $1.1 \mathrm{R} / \mathrm{min}$ & $1.76 \mathrm{R} / \mathrm{min}$. \\
\hline
\end{tabular}

There is reasonable agreement of the calculated and measured values when considering the effect of attenuation by the detector used to measure exposure. We believe that our calculated values are higher because we do not account for attenuation of the $x$-ray source by the detector measuring the exposure. This most likely explains why there is a greater difference in the comparison of the unfiltered example as there are more low-energy $\mathrm{x}$-rays that are absorbed by the detector. For this reason we use the measured values of exposure to determine the magnitude of interference caused by background radiation as the CT detector will attenuate some degree of low energy $\mathrm{x}$-rays before they scintillate.

The interfering background radiation is defined for this work as radiation that produces approximately $4.17 \mathrm{mR} /$ minute exposure at $304.8 \mathrm{~mm}$ from the detector (equivalent to 250 $\mathrm{mR} /$ hour at 12 inches from the detector). The exposure can then be calculated at $40 \mathrm{~mm}$ from the detector (representing the least amount of $x$-ray magnification for the SkyScan scanner) and is approximately $242 \mathrm{mR} /$ minute and at $230 \mathrm{~mm}$ from the detector (representing the greatest amount of magnification) or $7.32 \mathrm{mR} /$ minute. The greater the $\mathrm{x}$-ray magnification, the less interfering the background radiation.

The influence of interference or signal degradation is determined for any object-to-detector distance, odd, by the following equation:

$$
D_{\text {(odd) }}=\left[E_{s} /\left(E_{s}+E_{b(\text { odd })}\right)\right] \times 100,
$$

Where $E_{s}$ is the expected exposure at the detector from the x-ray source of the CT scanner, and $E_{b(o d d)}$ is the exposure expected at the detector from background radiation emitted at a distance odd from the detector. Figure 1 shows the expected signal degradation at the detector over the range of object-to-detector distance that is possible with the SkyScan CT system. The three different filter cases are represented. 


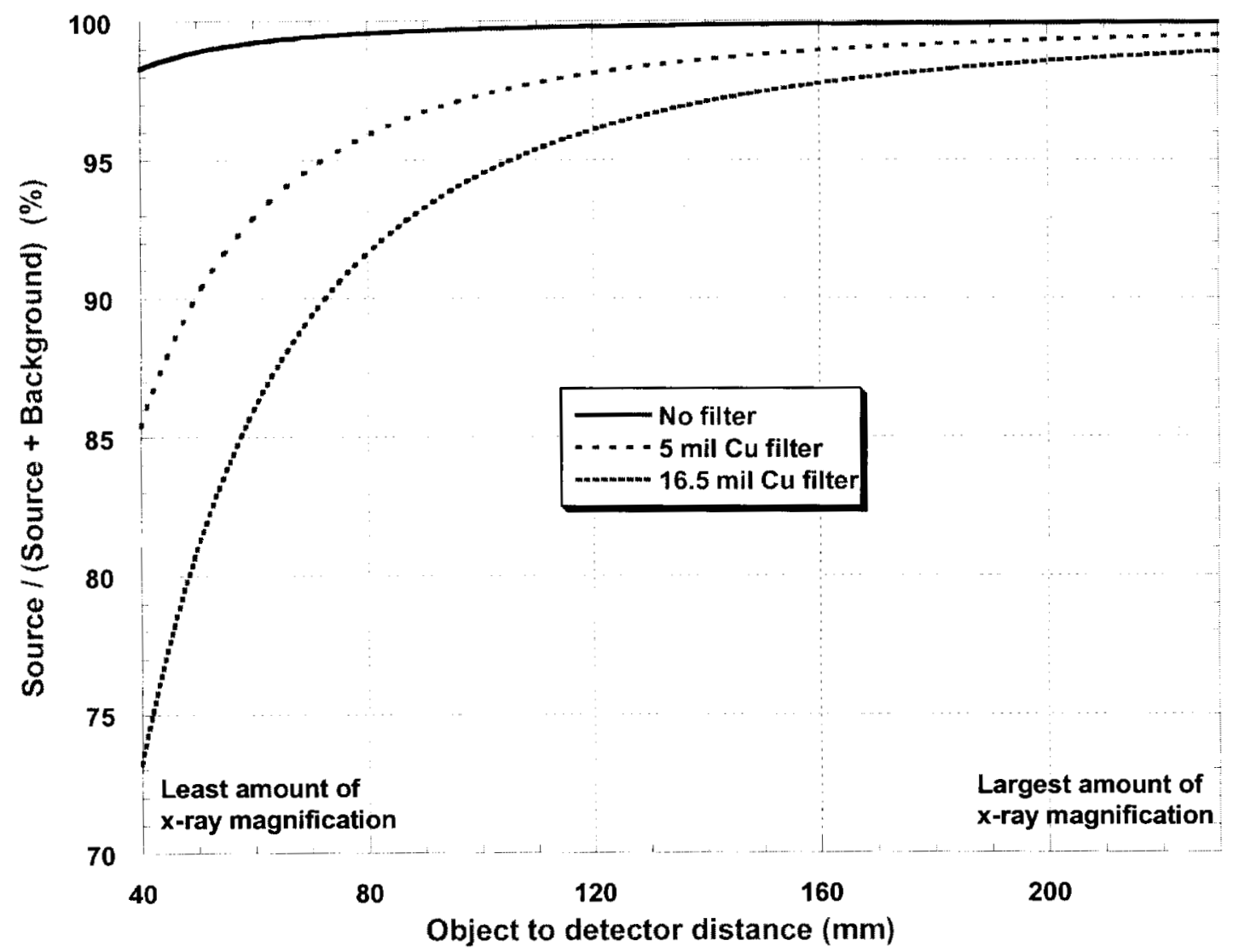

Figure 1: Graph showing the x-ray source to source plus background exposure ratios over the range of object-to-detector distance.

Another important factor to consider that can add to the signal degradation at the CT detector is the attenuation of the $x$-ray source by the object that is in the path of the source and detector. The influence of attenuation at some distance odd can be determined by using the following equation:

$$
A D_{\text {(odd) }}=\left[A E_{s} /\left(A E_{s}+E_{b(\text { odd })}\right] \times 100\right.
$$

Where $A E_{s}$ is the expected exposure at the detector from the $x$-ray source after being attenuated by the object. Figure 2 is a graph that shows the effect of attenuation of the $x$-ray source and the degradation of the signal at the detector caused by the interference from background radiation. This was determined at three different odd locations: 40,95 , and $230 \mathrm{~mm}$. Only the $0.127-\mathrm{mm} \mathrm{Cu}$ filter was used for these calculations. 




Figure 2: Graph showing the x-ray source to source plus background exposure ratios accounting for attenuation. Three curves represent attenuation from 0 to 90 percent for three different object-to-detector distances: 40, 95, and $230 \mathrm{~mm}$.

\section{RECOMDATIONS:}

The work performed here should be verified with experiments using a mock up of the CT system and detector.

The ratio of $x$-ray exposure to background exposure is significant especially when evaluating objects at lower magnification with the SkyScan system. Ideal computed tomography will require $90 \%$ attenuation of the $\mathrm{x}$-ray source by the object of interest, thereby compounding the problem. Also, this interference will be more prevalent at lower energy and current settings. It is possible to subtract the radiation background from the detected signal. This could be accomplished by measuring the background with the $x$-ray source off or shuttered and subtracting the measured value from the signal that is acquired with the $x$-ray source on. It is possible that this background measurement would only need to be taken once at the beginning and/or end of the CT scan and subtracted from each projection acquired. However, this would not work if the background radiation is dependent on the position (rotation) of the object. This technique should be investigated further with experiments, where the background image is acquired for many rotational positions and evaluated. 


\section{Exposure measurement on LLNL NME G-Machine made on 12/22/99}

Source: $160 \mathrm{kVp}, 33 \mathrm{~mA}$ Philips W-anode x-ray source Model \# MG 161 DOE \#3129928. Source to floor of cabinet is 1.345 meters.

Detector: 660 Victoreen meter using $660-3$ probe (SN 767). The meter was last calibrated 5/99 and is due $5 / 00$.

Note: At 0.5 meters there is less attenuation due to air on the low energy $x$-rays. This most likely explains the higher exposure rate for the unfiltered case at 0.5 meters. The filtered cases do not show this difference because the low energy $x$-rays are absorbed in the filter before they are absorbed in air.

\begin{tabular}{|c|c|c|c|c|c|c|}
\hline \multirow[b]{4}{*}{ REP } & \multirow{2}{*}{\multicolumn{6}{|c|}{$\begin{array}{c}\text { TABLE } 1 \\
\text { Exposure }(\mathrm{R}), \text { measurement at } 1 \text { meter }\end{array}$}} \\
\hline & & & & & & \\
\hline & \multicolumn{2}{|l|}{$\begin{array}{l}\text { No Filter } \\
10 \mathrm{~mA}\end{array}$} & \multicolumn{2}{|c|}{$\begin{array}{l}5 \text { mil Cu Filter } \\
10 \mathrm{~mA}\end{array}$} & \multicolumn{2}{|c|}{$\begin{array}{l}16.5 \mathrm{mil} \text { Cu Filter } \\
10 \mathrm{~mA}\end{array}$} \\
\hline & $130 \mathrm{kVp}$ & $80 \mathrm{kVp}$ & $130 \mathrm{kVp}$ & $80 \mathrm{kVp}$ & $130 \mathrm{kVp}$ & $80 \mathrm{kVp}$ \\
\hline 1 at $1 \mathrm{~min}$. & 89.1 & 68.4 & 8.4 & 2.88 & 4.07 & 0.84 \\
\hline 2 at $1 \mathrm{~min}$. & 79.7 & 68.6 & 8.4 & 2.9 & 4.18 & 0.786 \\
\hline 3 at $1 \mathrm{~min}$. & 89.3 & 68.3 & 8.5 & 2.91 & 4.17 & 0.795 \\
\hline 4 at $1 \mathrm{~min}$. & 89.2 & & & & & \\
\hline Expected at $250 \mathrm{~mm}, 0.1 \mathrm{~mA}$ & 13.892 & 10.94933 & 1.349333 & 0.463467 & 0.6624 & 0.12912 \\
\hline 1 at $2 \mathrm{~min}$. & & & 17.3 & & & \\
\hline
\end{tabular}

\begin{tabular}{|c|c|c|}
\hline & \multicolumn{2}{|c|}{$\begin{array}{c}\text { TABLE } 2 \\
\text { Exposure }(R), \text { measurement at } 0.5 \text { meter }\end{array}$} \\
\hline & $\begin{array}{l}\text { No Filter } \\
1 \mathrm{~mA}\end{array}$ & $\begin{array}{l}5 \text { mil Cu Filter } \\
10 \mathrm{~mA}\end{array}$ \\
\hline REP & $130 \mathrm{kVp}$ & $130 \mathrm{kVp}$ \\
\hline 1 at $1 \mathrm{~min}$. & 52 & 35.5 \\
\hline 2 at $1 \mathrm{~min}$. & 52 & 35.8 \\
\hline 3 at $1 \mathrm{~min}$. & 52 & 35.8 \\
\hline Expected at $250 \mathrm{~mm}, 0.1 \mathrm{~mA}$ & 20.8 & 1.428 \\
\hline
\end{tabular}

\begin{tabular}{|c|c|c|}
\hline & \multicolumn{2}{|c|}{$\begin{array}{l}\text { TABLE } 3 \\
\text { Exposure }(R), \text { measurement at } 1.2 \text { meter }\end{array}$} \\
\hline & $\begin{array}{l}\text { No Filter } \\
10 \mathrm{~mA}\end{array}$ & $\begin{array}{l}5 \mathrm{mil} \text { Cu Filter } \\
10 \mathrm{~mA}\end{array}$ \\
\hline REP & $130 \mathrm{kVp}$ & $130 \mathrm{kVp}$ \\
\hline 1 at $1 \mathrm{~min}$. & 60.1 & 6.39 \\
\hline 2 at $1 \mathrm{~min}$. & 60 & 6.41 \\
\hline 3 at $1 \mathrm{~min}$. & 59.9 & 6.39 \\
\hline Expected at $250 \mathrm{~mm}, 0.1 \mathrm{~mA}$ & 13.824 & 1.473792 \\
\hline
\end{tabular}




\section{APPENDIX - A: Computed exposure from an $\mathrm{x}$-ray tube operated at $130 \mathrm{kVp}$}

The exposure expected at the detector of a computed tomography (CT) scanner can be calculated for the purpose of estimating the difficulty that is expected from image corruption that occurs as a result of decay radiation.

Using a software program called TUBEDAT [RYO98], the $\mathrm{x}$-ray spectra produced for three different filter conditions Is calculated. Only a $130 \mathrm{kVp}$ tube potential on a $\mathrm{W}$-anode with a Be window and air flight path is considered. We calculated: 1) no added filtration, 2) 0.005 inch Cu filtration, and 3) 0.0165 inch Cu filtration. The inputs to the code are set so that we obtained spectra, $\Phi(E)$, at a distance of $1 \mathrm{~m}$ and for a current of $1 \mathrm{~mA}$, where E represents energy. The three spectra are shown in Figure 1.

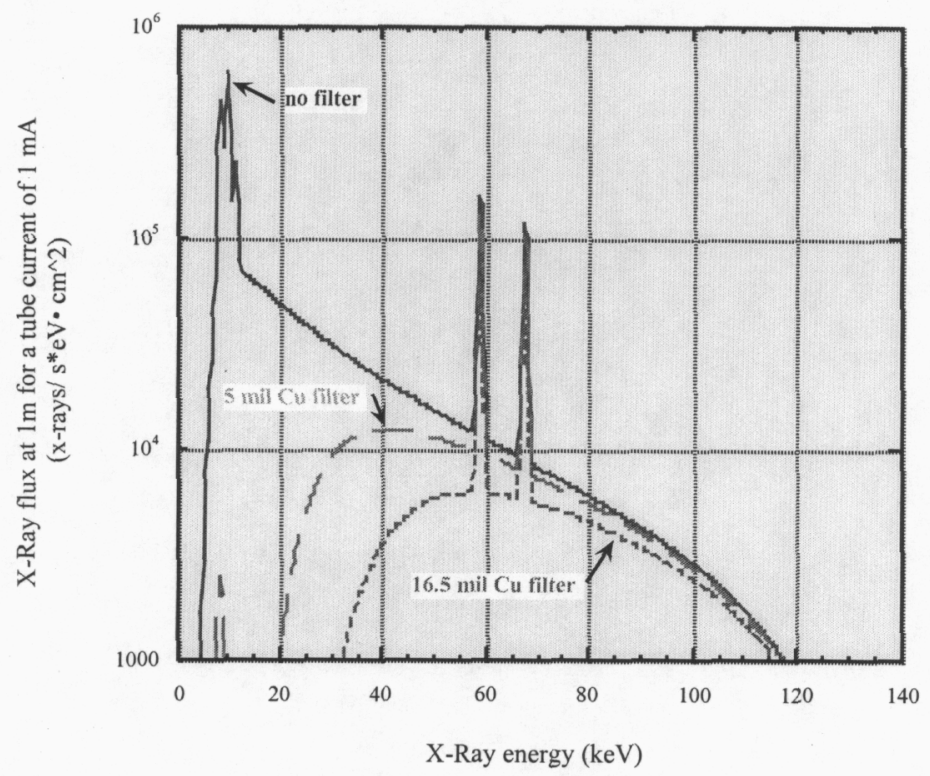

Figure 1 Calculated 130-kV x-ray spectra for three different filters.

The energy deposition coefficients for air are tabulated to derive exposure from the spectra of Figure 1 [GRAH99, NBS64]. The tabulated values are fitted with an arbitrary equation in order to facilitate spreadsheet computation. The tabulated data is shown as points in Figure 2 and the equation, $\mu(\mathrm{E})$, is given as a line. The equation is within $3 \%$ of the tabulated values at every point. The fitted equation is:

$$
y=a^{(b / x)}+c+d x^{e}+f x^{(g / x)},
$$

where:

$$
\begin{array}{ll}
\mathrm{a}= & 24.257, \\
\mathrm{~b}= & 0.002256, \\
\mathrm{c}= & -19.845, \\
\mathrm{~d}= & 0.018933, \\
\mathrm{e}= & -1.4631, \\
\mathrm{f}= & -4.4028, \\
\mathrm{~g}= & 0.0074272 .
\end{array}
$$

The energy deposit, $\mathrm{E}_{\mathrm{d}}$, then is given by:

$$
\mathrm{E}_{\mathrm{d}}=\left\{\left[1-\mathrm{e}^{(\mathrm{T} \mu(\mathrm{E})}\right] / \mathrm{T}\right\} \int \mathrm{E} \Phi(\mathrm{E}) \mathrm{dE},
$$


where $\mathrm{T}$ is the (air) detector areal density in mass/area. The result is not sensitive to $\mathrm{T}$ so long as $\mathrm{T} \mu(\mathrm{E}) \gg$ 1 ; for this work we use $0.001 \mathrm{~g} / \mathrm{cm}^{2}$. Using the conversion constant of $1.6 \times 10^{-14} \mathrm{~g} / \mathrm{rad} \mathrm{eV}$, converting to time units of minutes

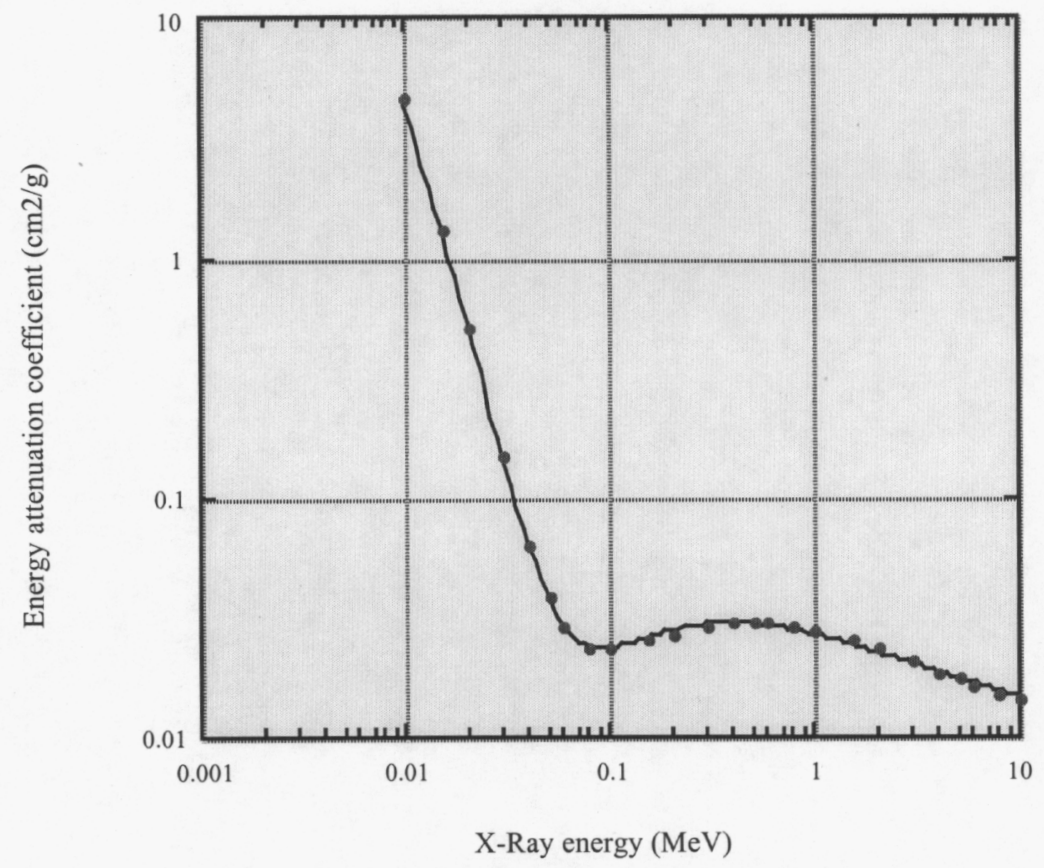

Figure 2 Tabulated energy deposition coefficients in air [NBS64] along with functional fit.

and converting to exposure using a conversion constant of $1.14 \mathrm{R}=1.0 \mathrm{rad}$ in air [GRA57] yields the results of Table 1.

Table 1 Computed exposure for three spectra

\begin{tabular}{lc} 
spectrum & $\begin{array}{l}\text { exposure }(\mathrm{R} / \mathrm{min}) \\
\text { for } 1 \mathrm{~mA} \text { at } 1 \mathrm{~m}\end{array}$ \\
\hline no filter & 97 \\
$5 \mathrm{mil} \mathrm{Cu}$ & 2.4 \\
$16.5 \mathrm{mil} \mathrm{Cu}$ & 1.1
\end{tabular}

These results can be compared to measured exposure for these conditions that are given in Table 2

Table 2 Measured exposure for three spectra

\begin{tabular}{lc} 
spectrum & $\begin{array}{l}\text { exposure }(\mathrm{R} / \mathrm{min}) \\
\text { for } 1 \mathrm{~mA} \text { at } 1 \mathrm{~m}\end{array}$ \\
\hline no filter & 8.7 \\
$5 \mathrm{mil} \mathrm{Cu}$ & 0.89 \\
$16.5 \mathrm{mil} \mathrm{Cu}$ & 0.41
\end{tabular}

We expect that the detector window has a large impact on the measurements due to absorption of the softer spectra. Taking this into account, these results show reasonable agreement.

\section{REFERENCES}

[GRA57] American Institute of Physics Handbook, Second Edition, D.E. Gray, editor, McGraw Hill (1957) 
[GRAH99]Curtis Graham, LLNL personal communication 1999.

[NBS64] Physical Aspects of Irradiation, Recommendations of ICIU, Handbook 85, US Department of Commerce, National Bureau of Standards, March 31, 1964.

[RYO98] Dick Ryon, LLNL personal communication 1998. 